\title{
Promoting Student Engagement: The Efficacy of a Criminal Justice Short-Term Study Abroad Program
}

\author{
Jennifer E. Capps \\ Jennifer Bradford \\ Hyon Namgung \\ Metropolitan State University
}

\begin{abstract}
:
In this study, we assessed student engagement during a short-term, faculty-led criminal justice studyabroad course using elements of the National Survey of Student Engagement (NSSE). Study abroad education has been identified as a high-impact learning strategy but significant evidence to support its efficacy is limited, particularly when delivered in a short-term format. This study is a partial replication of Rourke \& Kanuka's Student Engagement and Study Abroad study (2012). We administered a pre/post survey comprised of selected NSSE and criminal justice content-specific questions to a total of 101 undergraduate students at a major metropolitan university. The surveys were administered over a period of two years from five different courses traveling to three different destinations for study abroad education. A comparison of responses from the pre- and post-tests indicated that student engagement increased after participation in their short-term study abroad program. Student knowledge of international criminal justice systems also improved. The study results are limited by a small sample size which required a non-paired, pre- and post-testing comparison. Future research should focus on engaging a larger sample size which would allow for matched pre- and post-testing.
\end{abstract}

\section{Introduction}

Study abroad courses have long been touted by students and faculty alike as life-changing educational and personal growth opportunities. Students are given the chance to experience first-hand the real world as their classroom. The explosion of globalization at the end of the twentieth century has helped attract a greater number of students from more diverse fields and backgrounds to study abroad (Donnelly-Smith, 2009). Researchers have struggled to operationalize these experiences and gather evidence that would validate the value of study abroad (Rourke \& Kanuka, 2012).

In the case of criminal justice study abroad coursework, students witness international court hearings, compare and contrast policing in a global context, and apply economic, sociocultural, and political experiences to criminal justice concepts. This introduction to international experiences is of particular importance in developing well-rounded and civically-engaged graduates. Study abroad programs are disseminated in several formats and often vary in length, pedagogical approach, type of accommodations, and language requirements which result in broad experiences that are difficult to assess as specific markers of success (Engle \& Engle, 2003; Rourke \& Kanuka, 2012). 


\section{Study Abroad as a High-Impact Learning Strategy}

Study abroad education has been identified as a high-impact learning strategy linked with student engagement, however research on the topic is sparse and the research which does exist offers limited empirical support for short-term, study abroad in higher education (Asay, Younes, \& Moore 2006; Dekeyser, 2010; Rourke \& Kanuka, 2012). Most evaluation of study abroad programming has focused on learning outcomes associated with additional-language skills and intercultural competence. Research is lacking about students' disciplinary knowledge and personal and professional development. Across these studies, conclusions are equivocal. Intercultural competence, which includes awareness and understanding of culturally-diverse people and situations, often yields differences in students' scores, before and after study abroad. While this difference is noted, it is not often a large enough difference to move students to the next developmental stage of growth (Asay, Younes, \& Moore 2006; Bataller, 2010; Black \& Duhon, 2006; Douglass \& Jones-Rikkers, 2001; Emert $\&$ Pearson, 2007). Overall conclusions about the effect of study abroad on language-acquisition skills reflect that extended visits do often result in greater language achievement (Martinsen, Baker, Dewey, Brown, \& Johnson, 2010; Rees \& Klapper, 2007). Very few researchers have evaluated the impact of study abroad on the remaining outcomes, specifically disciplinary knowledge as well as personal and professional development. While these outcomes are informally associated with study abroad and often used to justify them, the empirical evidence is lacking (Rourke \& Kanuka, 2012).

Short-term study abroad courses, which are defined as those lasting shorter than eight weeks in duration, are among the most common type of undergraduate study abroad programming in the United States (Donnelly-Smith, 2009). According to the Institute of International Education's 2016 Open Doors Report, 63\% of US students who studied abroad did so in the short-term format. The increase in popularity of short-term study abroad courses is due to several factors: they are generally more affordable, appeal to students who are not willing or cannot commit to a semester or year-long program and allow students in structured and highly accredited programs not to fall behind in their coursework (Donnelly-Smith, 2009). While there is little formal research to support best practices and learning outcomes for short-term study abroad programming, one study conducted by Paige, Fry, Stallman, Josic, and Jon at the University of Minnesota, in 2009, was among the first to demonstrate the efficacy of short-term study abroad programming. In their study, they surveyed more than 6,000 alumni from 20 universities and found that there was no significant difference in global engagement (defined as the degree of international and domestic civic commitment and volunteerism) between short-term and longer-term study abroad students.

\section{Student Engagement}

Identifying factors that promote student engagement has become a priority at many institutions of higher learning across the country as student engagement has been linked with increased student learning. Student engagement is defined as a "reflection of the extent to which students engage in learning activities that have a demonstrable impact on their intellectual and psychosocial development" (NSSE, 2016). Student engagement represents two critical features of collegiate quality. The first is the amount of time and effort students put into their studies and other educationally purposeful activities. The second is how the institution deploys its resources, organizes the curriculum, and offers other learning opportunities that decades of research demonstrates are linked to student learning. 
Further, student engagement refers to the degree of attention, curiosity, interest, optimism, and passion that students show when they are learning or being taught, which also extends to the level of motivation they have to learn and progress in their education. Generally speaking, the concept of "student engagement" is predicated on the belief that learning improves when students are inquisitive, interested, or inspired, and that learning tends to suffer when students are bored, dispassionate, disaffected, or otherwise "disengaged." "Stronger student engagement" or "Improved student engagement" are common instructional objectives expressed by educators. (Glossary of Educational Reform, 2016).

Although this study does not specifically focus on students housing status, it should be noted that all study participants attended a 100\% commuter campus and thus lived off campus. Further, a significant number of students in the study are considered non-traditional or adult learners, with an average age of 25 or older. This is notable because commuter students have historically struggled to engage with their university at the same rate as their residential counterparts (Alfano \& Eduljee, 2013). Further, engaging commuter students in study abroad presents opportunities to broaden their worldviews and create stronger university connections before, during and after their study abroad experience (Tyner, 2013). A study abroad program changes a traditional learning environment by uniting students of all backgrounds on a more equal playing field. The current study would be remiss to ignore mentioning this population even though our current hypotheses do not directly address this as a variable at this time.

\section{National Survey of Student Engagement (NSSE)}

Through its student survey, The National Survey of Student Engagement (NSSE) annually collects information at hundreds of four-year colleges and universities about first-year and senior students' participation in programs and activities that institutions provide for their learning and personal development (NSSE, 2017). The results provide an estimate of how undergraduates spend their time and what they gain from attending college.

The NSSE provides participating institutions a variety of reports that compare their students' responses with those of students at self-selected groups of comparable institutions. Comparisons are available for ten Engagement Indicators, six High-Impact Practices, and all individual survey questions. Each November, NSSE also publishes its Annual Results, which reports topical research and trends in student engagement results. NSSE researchers also present and publish research findings throughout the year.

Survey items represent empirically-confirmed "good practices" in undergraduate education. That is, they reflect behaviors by students and institutions that are associated with desired outcomes of attending a university. NSSE does not assess student learning directly, but survey results point to areas where colleges and universities are performing well and aspects of the undergraduate experience that could be improved (NSSE, 2017).

Institutions use their data to identify aspects of the undergraduate experience inside and outside the classroom that can be improved through changes in policies and practices more consistent with good practices in undergraduate education. This information is also used by prospective college students, their parents, college counselors, academic advisers, institutional research officers, and 
researchers to learn more about how students spend their time at different colleges and universities and what they gain from their experiences.

This study seeks to explore acquisition of intercultural competence, student disciplinary knowledge, as well as personal and professional development of Criminal Justice and Criminology (CJC) students participating in short-term, faculty-led study abroad courses from 2016-2017. The CJC department is one of the largest majors at MSU Denver, drawing approximately 900 students annually. Study abroad education is new to the CJC Department with the first faculty-led, short-term program to London, England, commencing in 2014. To date, the department runs three study abroad courses annually (England, Netherlands, and South Korea). Because this method of instruction is new to the department, we have only just begun to assess its efficacy. While students and faculty alike often remark that studying abroad has profound effects on students, researchers have had a difficult time operationalizing this impact (Rourke \& Kanuka, 2013). This study will utilize a modified version of the NSSE to address this gap.

\section{Hypotheses}

This study focuses on study abroad as a high-impact learning strategy and a vehicle for student engagement. Additionally, this study seeks to obtain information about students' perception of, exposure to, and knowledge of global criminal justice systems before and after their study abroad course. To assess the effect of short-term study abroad programs on students' perceptions, we developed two hypotheses:

Hypothesis 1: Participation in study abroad education will improve the level of student engagement as evidenced by the mean NSSE scores will increase after participation in a shortterm study abroad program.

Hypothesis 2: Participation in study abroad education will increase student knowledge of global criminal justice systems as evidenced by the mean scores related to the disciplinary knowledge will increase after participation in a short-term study abroad program.

\section{Methods}

To assess engagement with this population, the current study utilized a cross-sectional survey designed to serve as a pilot for a potential longitudinal study in the future. Relevant survey questions were drawn from the NSSE and additional "criminal justice specific" survey questions were added to create an original survey instrument that contains 26 Likert-scale (strongly agree to strongly disagree) questions and four additional demographic questions. The scale questions were intended to appropriately reflect relevant categories of assessing engagement, such as the NSSE benchmarks of Engagement Activities, Campus Environment, and Classroom Experiences. These benchmarks can be further broken down into pre-identified NSSE engagement indicators to include Reflective and Integrative Learning, Supportive Environment, Perceived Gains and Satisfactions, Student-Faculty Interactions, and Higher-Order Learning. This operationalization is consistent with a prior study in measuring student engagement (e.g., Rourke \& Kanuka, 2012).

To accurately assess engagement, these surveys were distributed in an identical pre/post survey design where the study abroad class/experienced what was being assessed as the high impact engagement practice. The surveys were disseminated to all students who participated in three separate 
study abroad programs offered by the Department of Criminal Justice and Criminology at MSU Denver. The three programs travel to England, The Netherlands, and South Korea. These programs are short-term, faculty-led study abroad classes that consist of a semester-based, 3-credit course; the actual international travel takes place over the course of seven to nine days (typically over Spring Break, Fall Break, or the May semester). We chose to include all three study abroad trips not only to increase the sample but also because we felt confident in the consistency of instruction across the trips. For consistency across the variable topics, the format and curricula of the trips are all virtually identical with the major difference being the geographic location and time of year. The instructors each took a similar teaching approach, the semester-based course was set up the same, and the syllabi all required the same types of assignments. Finally, though anecdotal, we had a handful of students take two of these trips (one student went on all three) and they all indicated the class format was essentially identical, even though the geographic location was different. Their experiences varied, of course, but from an academic assessment perspective, we feel that aggregating the courses is appropriate. Thus, a typical program would allow students to interact with comparative and international criminal justice components to include (but not limited to) police, courts, prisons, juvenile programs, and counterterrorism. The class curriculum is comparable to a traditional semester class where assignments, class participation, and examinations are required for assessment of a final grade. Within these assignments and assessments, it is common to require students to critically compare the criminal justice components as they know them in the United States with their appropriate counterpart abroad. As would be expected, the majority of the points acquired for grading purposes occur through attendance and participation during the international travel period. Thus, it is this period of time that is specifically targeted for assessment of student engagement.

Students were given the opportunity to complete a pre-survey at required class sessions scheduled prior to international travel. The post-survey was made available on the final travel day, usually at an airport. Due to a predictably small sample and to avoid a high likelihood of the loss of confidentiality, this study did not match the pre- and post-surveys, nor did we initially code based upon the specific study abroad program or time-frame (only one study abroad program runs at a time). Since this was meant to be an exploratory survey on the front-end of a potential longitudinal study, aggregating the three trips allowed our study to have a smoother and quicker IRB approval process. Additionally, study abroad trips were planned at the whim of instructor availability and semester timing, thus a systematic schedule of the trips had not yet been established. Now that the program is more well-established, future trips will be on a predictable schedule and since initial results have been positive, future iterations of this study will begin to match pre- and post-survey responses and code by trip and timeframe. It should also be noted that the study abroad program is a designated "variable topics" course and does not restrict students from enrolling in multiple study abroad programs. Thus, there are some students who have participated in multiple iterations of this program and may have completed the surveys each time. All survey procedures and methods utilized in this study adhered to the preapproved conditions required by MSU Denver's Institutional Review Board.

From Spring 2016 to Spring 2017, a total of 64 students enrolled in four study abroad classes (England, the Netherlands, South Korea, and the Netherlands) allowing a possible 128 pre- and postsurveys. A total of 101 surveys were collected ( $N=56$ pre-survey and $\mathrm{N}=45$ post-survey). Currently, the department has a maximum enrollment of 20 students for instructor management purposes. 
Therefore, a small sample size was anticipated and has been accounted for in subsequent analyses. Table 1 presents sample statistics of students who participated in the programs.

Table 1.

Descriptive Statistics of Study Abroad Participants

\begin{tabular}{llll}
\hline & & Pre-trip survey $(\mathrm{N}=56)$ & Post-trip survey $(\mathrm{N}=45)$ \\
\hline Sex & Male & $10(18.5 \%)$ & $13(28.9 \%)$ \\
\multirow{2}{*}{ Race } & Female & $44(81.5 \%)$ & $32(71.1 \%)$ \\
& White & $28(51.9 \%)$ & $21(46.7 \%)$ \\
& Hispanic & $15(27.8 \%)$ & $14(31.1 \%)$ \\
Age & Other & $11(20.3 \%)$ & $10(22.2 \%)$ \\
& $18-22$ & $25(47.2 \%)$ & $20(44.4 \%)$ \\
& $23-30$ & $17(32.1 \%)$ & $17(37.8 \%)$ \\
& 31 or older & $11(20.7 \%)$ & $8(17.8 \%)$ \\
\hline
\end{tabular}

\section{Instruments and Data Analysis}

The surveys included four categories of Engagement Indicators based on the NSSE's Benchmarks of Effective Educational Practice: reflective and integrative learning, perceived gains and satisfaction, student-faculty interaction, and higher-order learning. An additional category, Knowledge of International Criminal Justice, was included to measure the change in students' knowledge of international criminal justice issues before and after the study abroad programs.

Each subcategory uses a four-point Likert scale, ranging from Strongly Agree to Strongly Disagree. We reversely coded this item (i.e., 1=Strongly Disagree, 2=Disagree, 3=Agree, 4=Strongly Agree) for analysis. A Reliability index (i.e., Cronbach's alpha) shows that all subcategories have high reliabilities (ranging from $a=.87$ to $a=.92$ ). As noted earlier, two groups in our sample (pre-test and post-test) are not independent, but they are not paired as well. Therefore, we did not attempt to conduct either paired-sample t-tests nor independent t-tests because of potentially biased results from those analyses. Due to a limited choice of statistical analyses, we tested the changes in subjects using measures of central tendency (i.e., mean, median, mode, and standard deviations), including confidence intervals. That is, the data were analyzed using descriptive statistics of each subcategory to investigate the change in students' perceptions on engagement indicators after taking part in study abroad programs. In addition, 95\% confidence intervals are visually checked to see if there is a significant overlap between errors of pre- and post-tests (Cumming \& Finch, 2005). 
Table 2.

Descriptive Statistics of Pre- and Post-Trip Indicators

\begin{tabular}{|c|c|c|c|c|c|c|}
\hline \multirow[b]{2}{*}{ Reflective and Integrative Learning } & \multicolumn{3}{|c|}{ Pre-trip Survey } & \multicolumn{3}{|c|}{ Post-trip Survey } \\
\hline & $\mathrm{N}$ & M & $\mathrm{SD}$ & $\mathrm{N}$ & M & SD \\
\hline 1. Connected your learning to societal problems or issues & 56 & 3.48 & 0.60 & 45 & 3.80 & 0.40 \\
\hline 2. Included diverse perspectives in course discussions or assignments & 56 & 3.46 & 0.57 & 45 & 3.80 & 0.40 \\
\hline 3. Examined the strengths and weaknesses of your own views on a topic or issue & 56 & 3.45 & 0.63 & 45 & 3.58 & 0.54 \\
\hline $\begin{array}{l}\text { 4. Tried to better understand someone else's views by imagining how an issue looks } \\
\text { from his or her perspective }\end{array}$ & 56 & 3.45 & 0.60 & 45 & 3.76 & 0.43 \\
\hline 5. Learned something that changed the way you understand an issue or concept & 56 & 3.55 & 0.54 & 45 & 3.76 & 0.48 \\
\hline 6. Connected ideas from your courses to your prior experiences and knowledge & 56 & 3.52 & 0.63 & 45 & 3.76 & 0.43 \\
\hline 7. Encouraging contact among students from different backgrounds & 56 & 3.32 & 0.69 & 45 & 3.73 & 0.45 \\
\hline \multicolumn{7}{|l|}{ Perceived Gains and Satisfaction } \\
\hline 8. Thinking critically and analytically & 56 & 3.57 & 0.66 & 45 & 3.76 & 0.43 \\
\hline 9. Working effectively with others & 56 & 3.48 & 0.66 & 45 & 3.60 & 0.62 \\
\hline 10. Developing or clarifying a personal code of values and ethics & 56 & 3.54 & 0.54 & 45 & 3.69 & 0.47 \\
\hline 11. Understanding people of other backgrounds & 56 & 3.46 & 0.63 & 45 & 3.87 & 0.34 \\
\hline 12. Solving complex real-world problems & 56 & 3.25 & 0.77 & 45 & 3.64 & 0.57 \\
\hline 13. Being an informed and active citizen & 56 & 3.34 & 0.72 & 45 & 3.67 & 0.48 \\
\hline \multicolumn{7}{|l|}{ Student-Faculty Interaction / Engagement Activities } \\
\hline 14. Had a quality interaction with a faculty member outside of the classroom & 56 & 3.09 & 0.84 & 45 & 3.73 & 0.58 \\
\hline 15. Discussed career plans with a faculty members & 55 & 3.02 & 0.89 & 45 & 3.56 & 0.62 \\
\hline 16. Discussed academic performance with a faculty member & 56 & 3.11 & 0.80 & 45 & 3.49 & 0.73 \\
\hline \multicolumn{7}{|l|}{ Higher-Order Learning/Classroom Experience } \\
\hline 17. Applying facts, theories, or methods to practical problems or new situations & 54 & 3.44 & 0.50 & 45 & 3.78 & 0.42 \\
\hline 18. Evaluating a point of view, decision, or information source & 54 & 3.54 & 0.57 & 45 & 3.73 & 0.45 \\
\hline 19. Forming a new idea or understanding from various pieces of information & 54 & 3.57 & 0.54 & 45 & 3.82 & 0.39 \\
\hline \multicolumn{7}{|l|}{ Knowledge of International Criminal Justice System } \\
\hline 20. Law enforcement & 56 & 2.54 & 0.85 & 45 & 3.44 & 0.59 \\
\hline 21. Corrections & 56 & 2.38 & 0.80 & 45 & 3.31 & 0.70 \\
\hline 22. Courts & 56 & 2.32 & 0.77 & 45 & 3.60 & 0.54 \\
\hline 23. History & 56 & 2.50 & 0.83 & 45 & 3.42 & 0.54 \\
\hline 24. Theory & 56 & 2.18 & 0.74 & 45 & 3.02 & 0.62 \\
\hline 25. Terrorism and counterterrorism & 55 & 2.45 & 0.69 & 45 & 3.29 & 0.66 \\
\hline 26. Overall international criminal justice systems & 56 & 2.29 & 0.82 & 44 & 3.50 & 0.59 \\
\hline
\end{tabular}




\section{Results}

\section{Reflective and Integrative Learning}

Table 2 presents an aggregated summary of pre- and post-trip surveys of all indicators. First, mean scores increased in all subcategories of "Reflective and Integrative Learning" after students finished study abroad courses. For example, students' perceptions of connecting to societal problems or issues increased from 3.48 to 3.80. These changes between pre- and post-tests are significant, as is presented in Appendix A. Among seven indicators, the difference of mean score was the greatest in the last subcategory — encouragement of contact among students from different backgrounds. This may not be surprising considering that students had ample opportunities to interact with other participants through study abroad programs. The increase of understanding of other societies and cultures after the study abroad program is consistent with prior research (e.g., Clarke \& Flaherty, 2009).

\section{Perceived Gains and Satisfaction}

All six subcategories also show increases of mean scores between pre- and post-trip surveys on this subcategory. More specifically, the increase of the mean score is the greatest in "Understanding people of other backgrounds" subcategory (from 3.46 to 3.87), followed by "Solving complex realworld problems" (from 3.25 to 3.64). As Appendix B indicates, all subcategories (except for "Working effectively with others") show significant improvements after students participated in study abroad programs. Through site visits to criminal justice agencies in different countries, participating students interacted with diverse people in other cultures and witnessed how other countries try to tackle their own challenges. We believe these experiences in foreign countries led to an increased understanding of diverse people and greater problem-solving skills.

\section{Student-Faculty Interaction}

The mean difference between pre- and post-trip surveys in the first item (i.e., quality interactions with faculty members outside of the classroom) was the greatest among the three areas although all improvements can be considered significant (see Appendix C). This difference is understandable because study abroad programs generally involve greater interactions between students and faculty members' formal and informal conversations through routine travel experiences, such as experiencing the same foods, culture, challenges, and enjoyment.

\section{Higher-Order Learning/Classroom Experiences}

The change in students' perceptions of "Higher-Order Learning/Classroom Experience" through study abroad programs is included in Table 5. Again, the mean scores increased in all three subcategories. More specifically, the first subcategory (i.e., applying facts, theories, or methods to practical problems or new situations) increased significantly relative to other areas after the trips. As Appendix D suggests, the changes of confidence interval show the significant improvements in all three subcategories. The increases can be attributed to the fact that students have many chances to apply their knowledge of the criminal justice system when they are in completely new environments or faced with new policies and programs.

\section{Knowledge of International Criminal Justice System}

Students believed their knowledge improved after the international trip and showed the most improvements in knowledge in the courts subcategory (from the mean score of 2.32 in pre-test to 3.6 
in post-test). Appendix $\mathrm{E}$ also shows that the changes in students' knowledge in all subcategories are significant. Theoretical knowledge of international criminal justice systems is the lowest both in preand post-trip surveys, but the mean score still increased after students experienced site visits and interactions with criminal justice agents in foreign countries.

\section{Discussion}

Study abroad programming is a high-impact learning strategy and a vehicle for student engagement. The goal of this study was to explore the impact of short-term, faculty-led study abroad programs on student engagement. Since these programs are based in a criminal justice and criminology department, the research question was broadened to include discipline-specific engagement outcomes. Thus, we set out to test two hypotheses:

Hypothesis 1: Participation in study abroad education will improve the level of student engagement as evidenced by the mean NSSE scores will increase after participation in a shortterm study abroad program.

Hypothesis 2: Participation in study abroad education will increase student knowledge of global criminal justice systems as evidenced by the mean scores related to the disciplinary knowledge will increase after participation in a short-term study abroad program.

Based on the survey data of students who participated in short-term study abroad programs that focused on criminal justice and criminology discipline, the results overall support our hypotheses. Regarding the first hypothesis, the mean scores of students' perceptions increased dramatically in all subcategories from pre-test to post-test of the Engagement Indicators: reflective and integrative learning, perceived gains and satisfaction, student-faculty interaction, and higher-order learning. Therefore, we find support for the idea that participation in a study abroad program will improve overall student engagement. As discussed later, it should be noted that a potential limitation to this result may be that more naturally engaged students are more inclined to participate in a study abroad program. However, the pre- and post-test results still support the finding that an increase in engagement occurred that can be directly related to the study abroad experience. Thus, it can be proffered that although previously-engaged students may be more inclined to participate in a study abroad program, their engagement increases even more after that participation.

Regarding the second hypothesis, students' knowledge of international criminal justice systems increased after participating in the study abroad trips in all areas tested. The mean scores of participants' perception of knowledge increased by almost one point in every area. For example, in the courts content area, students' pre-test mean score $=2.3$ while their post-test mean score $=3.6$. The study abroad programs require students to directly engage with comparative elements of the criminal justice discipline and subsequently write a critical paper and complete an assessment of knowledge. Thus, a natural increase in knowledge is expected; these results provide statistical support that this increase is significant.

This research produced encouraging results that provide further support for short-term study abroad programs being some of the most critical educational programs to benefit college students; this aligns with the NSSE's identification of study abroad education as a high impact practice (NSSE, 2016). Relative to other "high-impact practices," study abroad education has not been utilized by many 
colleges (NSSE, 2016). For example, only about $14 \%$ of seniors in the NSSE survey answered that they have completed or plan to complete study abroad programs, compared to $51 \%$ in internship and $72 \%$ in service-learning programs. This is not surprising because study abroad programs require a lot of additional work by faculty including engagement in additional training to prepare for potential health and safety issues while traveling abroad with students as well as coordinating numerous academic and logistical components (Goode, 2008). It has been observed anecdotally that small-group study abroad programs increase the amount of quality time with faculty members, during which time students seek academic and personal advice and/or suggestions about their curiosities. Informal settings where study abroad programs are held will also increase more natural and informal interactions between students and instructors. These anecdotal observations now have more formal statistical support as a result of this study.

The contribution of the results of this project to the criminal justice discipline is significant. Recent high-profile cases of American students (e.g., Amanda Knox, Otto Warmbier, etc.) who have experienced foreign criminal justice systems have negatively impacted views of international criminal justice comparisons. This illustrates the importance of educating criminal justice students on the variations of criminal justice matters throughout the world. Further, the results demonstrate the efficacy of short-term study abroad programming on the acquisition of knowledge related to international criminal justice.

Our study is not without limitations. First, selection bias may have played a role in students' perceptions in each category. Considering that our study abroad programs required significant financial investment and/or family support relative to other regular on-campus courses, it is likely that students who travel abroad are more willing to actively participate in the programs. In other words, it can be assumed that study abroad participants are more inclined to be impacted by the programs. However, it is worth mentioning that due to the characteristics of study abroad programs this issue will not be easily addressed (Tarrant, Rubin, \& Stoner, 2014).

Second, and related to the first limitation, students in our sample are from an urban, nontraditional, and commuter educational setting. In fact, half of our participants are 23 years old or older. Thus, we caution that the findings may not be generalizable to other traditional colleges who carry a lower mean age. Finally, our sample is not large enough to generalize the findings to all settings. Although we conducted surveys for all three study abroad programs in our department, only about 65 students participated in the programs. Continued sampling will give us a clearer understanding of students' change in perceptions.

The results presented here are considered preliminary and the study is on-going. Through continued research, we hope to establish a strong body of evidence demonstrating the efficacy of short-term study abroad programming. Our research intends to expand upon current methodology through a longitudinal approach and trend analysis; furthermore, we intend to add in direct comparison groups (non-study abroad criminal justice students) to assess an additional hypothesis not presented in this current study. Future research would greatly benefit from expanding upon the sampling frames to include a wider diversity of student populations from around the United States. Another area worthy of exploration would be to compare engagement of international students 
coming to the United States to the engagement of study abroad students. This approach would further isolate the impact of study abroad, regardless of geographic origin and location of the study.

\section{References}

Alfano, H. J., \& Eduljee, N. B. (2013). Differences in work, levels of involvement, and academic performance between residential and commuter students. College Student Journal, 47(2), 334-342.

Asay, S., Younes, M., \& Moore, T. J. (2006). Promoting cultural competence through international study experiences. In G. Berklitter (Ed.), International family studies: Developing curricula and teaching tools. 85-96. Binghamton, NY: Haworth Press.

Bataller, R. (2010). Making a request for a service in Spanish: Pragmatic development in the study abroad setting. Foreign Language Annals, 43(1), 160-175.

Black, H., \& Duhon, D. (2006). Assessing the impact of business study-abroad programs on cultural awareness and personal development. Journal of Education for Business, 81(3), 140-145.

Clarke III, I., Flaherty, T. B., Wright, N. D., \& McMillen, R. M. (2009). Student intercultural proficiency from study abroad programs. Journal of Marketing Education, 31(2), 173-181.

Cumming, G., \& Finch, S. (2005). Inference by eye: Confidence intervals and how to read pictures of data. American Psychologist, 60(2), 170-180.

Dekeyser, R. (2010). Monitoring processes in Spanish as a second language during a study-abroad program. Foreign Language Annals, 43(1), 80-92.

Donnelly-Smith, L. (2009). Global learning through short-term study abroad. Peer Review - Association of American Colleges and Universities, 12-15.

Douglass, C., \& Jones-Rikkers, C. (2001). Study-abroad programs and American worldmindedness: An empirical analysis. Journal of Teaching in International Business, 13(1), 55-66.

Emert, H., \& Pearson, D. (2007). Expanding the vision of international education: Collaboration, assessment, and intercultural development. New Directions for Community Colleges, 2007(138), 6775.

Engle, L., \& Engle, J. (2003). Study abroad levels: Toward classification of program types. Frontiers: The Interdisciplinary Journal of Study Abroad, 9, 1-20.

The Glossary of Educational Reform (2016). Student engagement. Great Schools Partnership. Retrieved from: http://edglossary.org/student-engagement/.

Goode, M. (2008). The role of faculty study abroad directors: A case study. Frontiers: The Interdisciplinary Journal of Study Abroad, 15, 149-172.

Institute of International Education (2016). Duration of U.S. study abroad, 2004/05-2014/15. Open Doors Report on International Educational Exchange. Retrieved from http://www.iie.org/opendoors.

Martinsen, R., Baker, W., Dewey, D., Brown, J., \& Johnson, C. (2010). Exploring diverse settings for language acquisition and use: Comparing study-abroad, service learning abroad, and foreign language housing. Applied Language Learning, 20(1-2), 45-69.

National Survey of Student Engagement (NSSE). (2017, April 17). Annals. Retrieved from: http://nsse.indiana.edu/html/about.cfm

National Survey of Student Engagement (2016). NSSE high-impact practices. Retrieved from: http://nsse.indiana.edu/Institutional_Report/High-Impact\%20Practices.pdf

Paige, R. M., Fry, G.W., Stallman, E. Josic, J., \& Jon, J.E. (2009). Study abroad for global engagement: Results that inform research and policy agendas. Paper presented at The Forum on Education Abroad's Annual Conference, Portland, Oregon.

Rees, J., \& Klapper, J. (2007). Analyzing and evaluating the linguistic benefit of residence abroad for UK foreign language. Assessment and Evaluation in Higher Education, 32(3), 331-353.

Rourke, L. \& Kanuka, H. (2012). Student engagement and study abroad. Canadian Journal of University Continuing Education, 38(1), 1-12.

Tarrant, M., Rubin, D., \& Stoner, L. (2014). The added value of study abroad: Fostering a global citizenry. Journal of Studies in International Education, 18(2), 141-161. 
Tyner, N. (2013). International cooperation: The study abroad experience. Michigan Academician, 41(3), $377-388$.

\section{Appendix A}

95\% Confidence Interval of Reflective and Integrative Learning for Pre- and Post-test

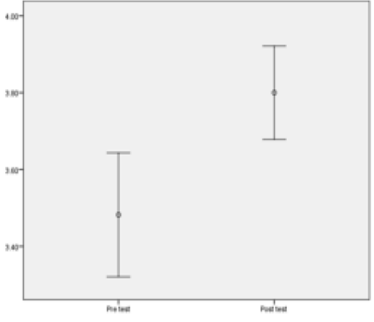

Connected your learning to societal problems or issues

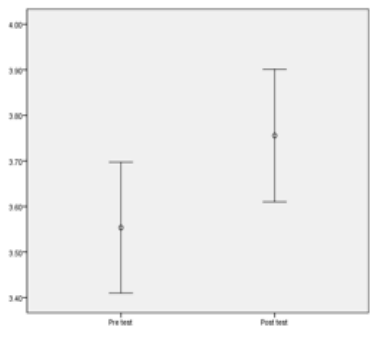

Learned something that changed the way you understand an issue or concept

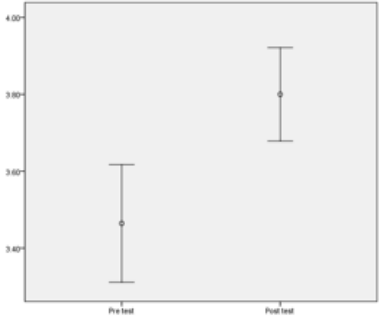

Included diverse perspectives in

course discussions or assignments

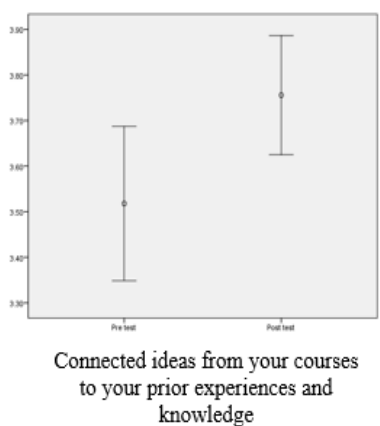

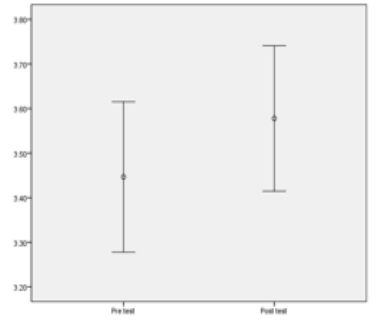

Examined the strengths and weaknesses of your own views on a topic or issue

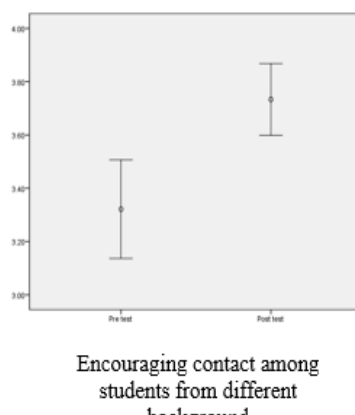

background

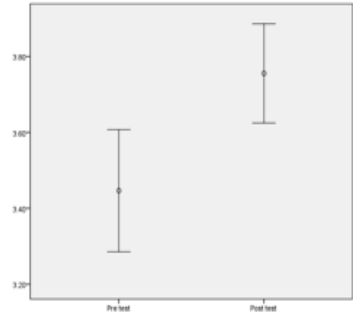

Tried to better understand someone else's views by imagining how an issues looks from his or her perspective

\section{Appendix B}

95\% Confidence Interval of Perceived Gains and Satisfaction for Pre- and Post-test
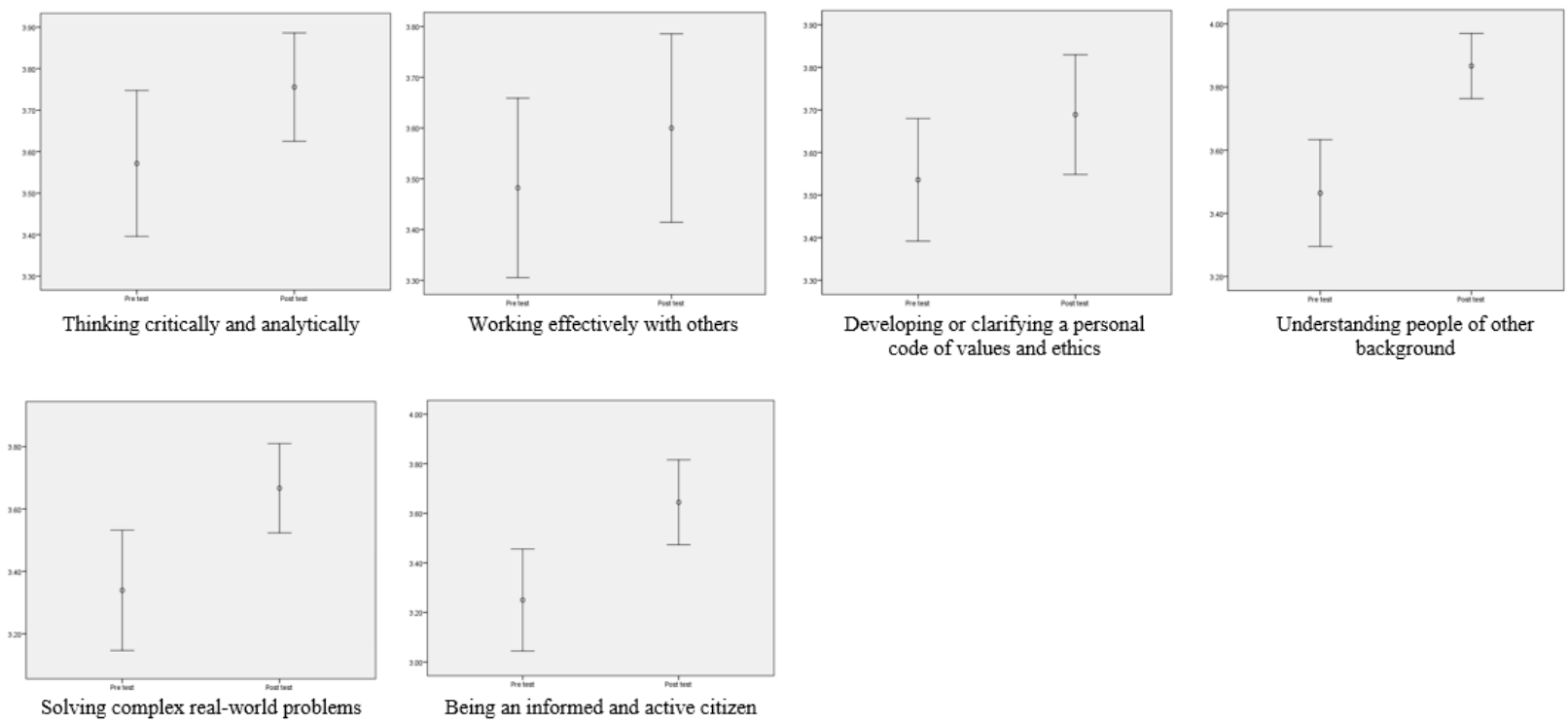
background 


\section{Appendix C}

95\% Confidence Interval of Student-Faculty Interaction/Engagement Activities for Pre- and Posttest

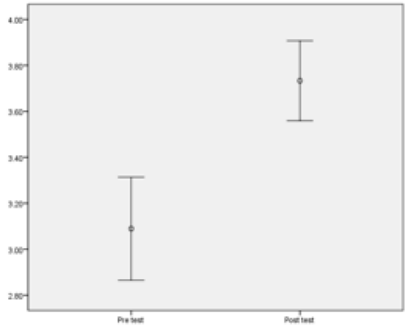

Had a quality interaction with a faculty member outside of the classroom

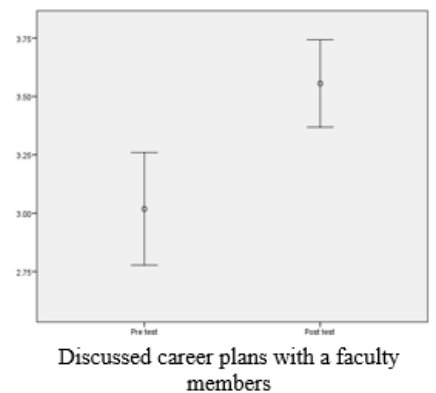

members

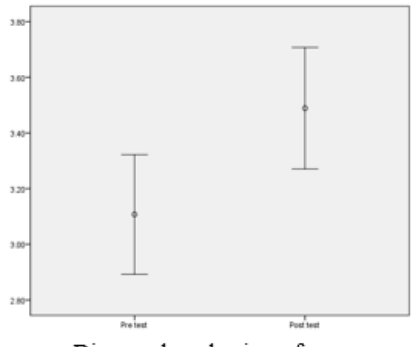

Discussed academic performance with a faculty member

\section{Appendix D}

95\% Confidence Intervals of Higher-Order Learning/Classroom Experiences for Pre- and Posttest
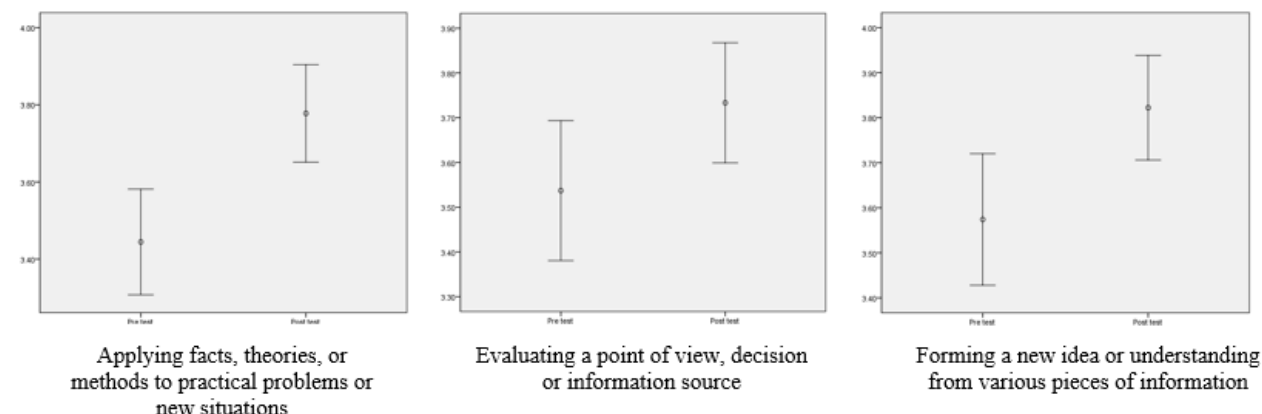
new situations

\section{Appendix E}

95\% Confidence Interval of Knowledge of International Criminal Justice System for Pre- and Posttest

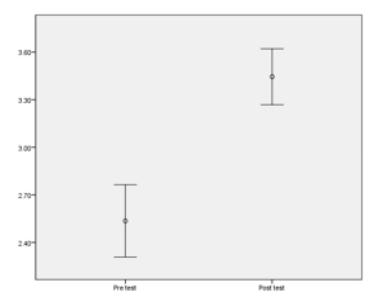

Law enforcement

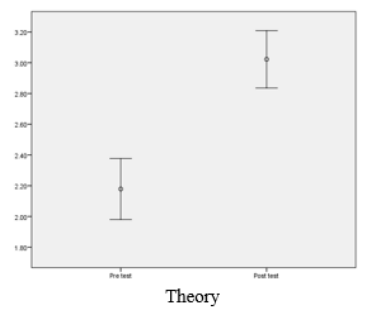

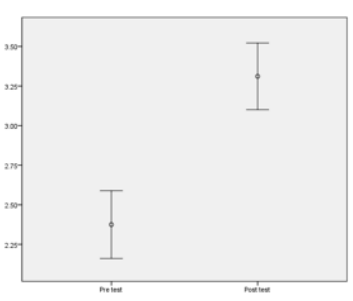

Corrections

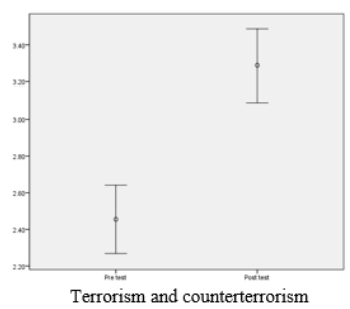

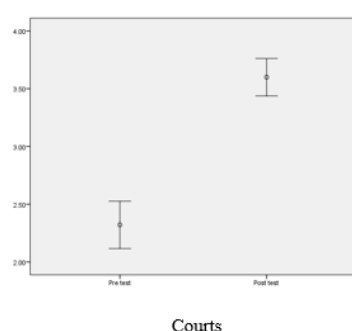

Courts

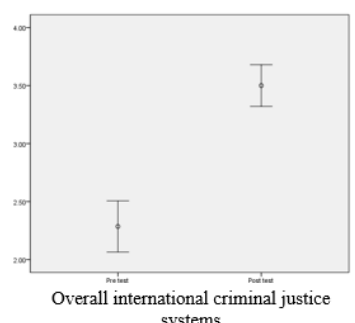

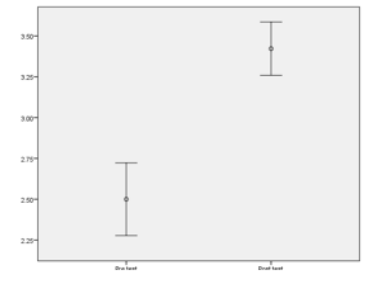

History 